\title{
The Effects of Dielectric Coatings on Electron Emission from Tungsten
}

\author{
Ala'a M. Al-Qudah, Shady S. Alnawasreh, Mazen A. Madanat, Oliwia Trzaska ${ }^{1}$, \\ Danuta Matykiewicz ${ }^{2}$, Saad S. Alrawshdeh ${ }^{3}$, Mark J. Hagmann ${ }^{4}$, Marwan S. Mousa* \\ Department of Physics, Mu'tah University, Al-Karak 61710, Jordan \\ ${ }^{1}$ Laboratory of Plastics, Wrocław University of Technology, Wroclaw 50371, Poland \\ ${ }^{2}$ Institute of Materials Technology, Poznan University of Technology, Poznan 61138, Poland \\ ${ }^{3}$ Department of Mechanical Engineering, Mu'tah University, Al-Karak 61710, Jordan \\ ${ }^{4}$ Department of Electrical and Computer Engineering, University of Utah, Salt Lake City, UT 84112, USA
}

*Correspondence to:

Mousa MS,

Tel: +962-79-5659761

Fax: $+962-3-2375540$

E-mail: mmousa@mutah.edu.jo

Received July 21, 2016

Revised December 2, 2016

Accepted December 5, 2016
Field electron emission measurements were performed on dielectric-coated tungsten emitters, with apex radii in the nanometer and micrometer range, which were prepared by electrochemical etching in $\mathrm{NaOH}$ solution. Measurements were performed in a field electron microscopy (FEM) with a base pressure $<10^{-6}$ Pascal $\left(10^{-8} \mathrm{mbar}\right)$. Four different types of dielectric were used, namely: (1) Clark Electromedical Instruments epoxylite resin, (2) Epidian 6 produced by Ciech Sarzyna S. A., (3) a Radionox solution of colloidal graphite; and (4) Molyslip $2001 \mathrm{E}$ compound $\left(\mathrm{MoS}_{2}\right.$ and $\left.\mathrm{MoS}\right)$. Currentvoltage measurements and FEM images were used to investigate the characteristics of these composite emitters, and to assess how the different types of dielectric coating affect the suitability of the composite emitter as a potential electron source.

Key Words: Field electron emitter, Dielectric layers, Composite emitters, Field electron microscope

\section{INTRODUCTION}

Field electron emission (FE) is the emission of electrons from the surface of a cathode under the influence of a high applied electrostatic field. This field is typically in the range 3 to $5 \mathrm{~V} /$ $\mathrm{nm}$, for a tungsten emitter with a work function of $4.5 \mathrm{eV}$ (Forbes, 2008; and take the reference field at which the barrier goes below the Fermi level as $14.1 \mathrm{~V} / \mathrm{nm}$ ).

As an electron source, the field emitter is particularly attractive due to its favorable emission properties and simple operating principle. The study of field emitters as potential electron sources for electron-beam instruments started around 1954 (Dyke \& Dolan, 1956). The first practical utilization of such sources appeared late in 1968 as a part of a scanning electron microscope (Crewe et al., 1968,1969; Crewe \& Wall, 1970).

Many experimental FE studies have been carried out on tungsten, lanthanum hexaboride and carbon fiber emitters. From the 1920s onwards, and for a long period thereafter, tungsten was the most widely used material for field emitters. Tungsten brings several benefits due to its favorable properties, such as ready availability in wire form, high melting point of $3,422^{\circ} \mathrm{C}$, hardness (strength), low vapor pressure, simplicity of emitter preparation by electrochemical etching, and durability. Techniques for preparing FE cathodes are well developed. Advances in vacuum technology have also been important, because a high-quality vacuum is essential for reliable operation of field emission cathodes.

These developments have enabled the widespread use of FE cathodes (Dyke \& Dolan, 1956; Zhu, 2001). Cathodefabrication technology based on electrolytic etching (Melmed, 1991) has been studied and enhanced. This technology now makes it possible to prepare a cathode tip with a diameter

(a) This is an open-access article distributed under the terms of the Creative Commons Attribution Non-Commercial License (http://creativecommons.org/licenses/by-nc/4.0) which permits unrestricted noncommercial use, distribution, and reproduction in any medium, provided the original work is properly cited.

Copyrights () 2017 by Korean Society of Microscopy 
of several nanometers. Composite micro-point cathodes have been prepared, with the aims of improving the emission characteristics needed for small bright electron sources, and reducing degradation of the electron emitter due to ion sputtering during emission (hence improving lifetime) (AlQudah et al., 2015; Latham \& Mousa, 1986; Mousa, 1990; Mousa et al., 1994, 2012; Mousa \& Al Share, 1999).

The research reported here continues this work on composite micro-point cathodes. It is based on investigating the current-voltage $(I[V])$ characteristics, determining the spatial emission current distributions via field electron microscopy (FEM), and noting the gross stability of these electron emission images. Various dielectric coatings have been used in preparing the composite cathodes, in a preliminary attempt to see if the nature of the coating makes any difference.

\section{MATERIALS AND METHODS}

The procedures used for coating tungsten emitters in the present work are the same as those described previously (AlQudah et al., 2015; Latham \& Mousa, 1986). In all cases, the micro-point, nano-apex metallic emitters used were electrolytically etched from $0.1 \mathrm{~mm}$ diameter tungsten wires of $99.95 \%$ purity (Goodfellow Metals, England), using a $2 \mathrm{M}$ solution of $\mathrm{NaOH}$, and were then ultrasonically cleaned. The coating procedure involved slowly dipping the emitter into resin and then carefully removing it, ensuring that only a thin film remained on its surface. This procedure was repeated 12 times, leading to a coating about 150 to $200 \mathrm{~nm}$ thick. The emitter was then carefully transferred to an oven and subjected to a resin-curing cycle of thirty minutes at $100^{\circ} \mathrm{C}$ to drive off the solvents, followed by another thirty minutes at $185^{\circ} \mathrm{C}$ to complete the curing (Al-Qudah et al., 2015; Latham \& Mousa, 1986).

The emitters were studied in a FEM pumped with a diffusionpump system having an additional liquid nitrogen trap. Base pressures of $<5 \times 10^{-6}$ Pascal $\left(10^{-8} \mathrm{mbar}\right)$ have been reached after baking the system at a temperature of $180^{\circ} \mathrm{C}$ for 12 hours with liquid nitrogen in the trap. In the FEM, the separation between the cathode and the anode was standardized at $\sim 10$ $\mathrm{mm}$, and a current-limiting resistor of $100 \mathrm{M} \Omega$ was used. The FEM images were recorded by a digital camera placed outside a window of the vacuum system.

For the $I(V)$ measurements, a high-voltage power supply was used to apply a high negative voltage to the cathode. The emission current was measured with a Keithley 485 autoranging pico-ammeter (Madanat et al., 2015). Fig. 1 shows a schematic diagram of the FEM, including the diffusion pump system.

\section{RESULTS}

As indicated above, investigations have been carried out for tungsten emitters and different coatings, namely: (1) Clark Electromedical Instruments epoxylite resin (England), (2) Epidian 6 produced by Ciech Sarzyna S.A. (Poland), (3) a Radionox solution of colloidal graphite; and (4) Molyslip $2001 \mathrm{E}$ compound $\left(\mathrm{MoS}_{2}\right.$ and $\left.\mathrm{MoS}\right)$. As indicated above, the results presented here are the $I(V)$ characteristics and the related FEM images. We also compare these results with the

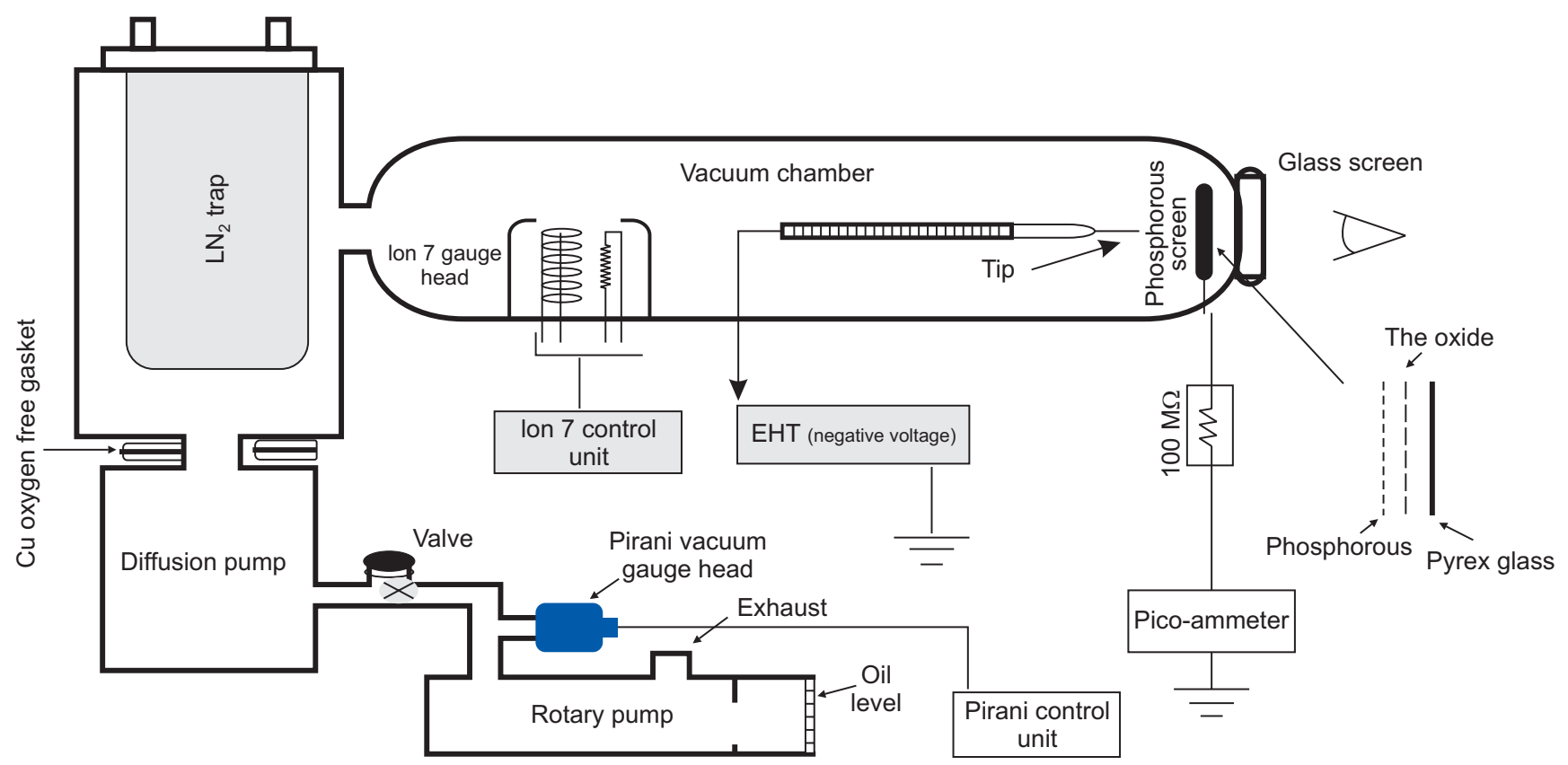

Fig. 1. Schematic diagram of a field electron microscope with a diffusion-pumped vacuum chamber. 
equivalent results for the uncoated tungsten microemitters.

\section{Composite Tungsten: Clark Electromedical Instruments Epoxylite Resin Tip}

First, we determined the emission characteristics of an uncoated tungsten tip, as shown in Fig. 2. Fig. 3 shows the related FEM images, for selected values of the voltage and related current. In this case, as in all cases below, the ranges of current and voltage used are shown in Table 1 (in this case as part of the data for "Emitter 1").

After coating with Clark Electromedical Instruments epoxylite resin, the voltage applied to the composite emitter was slowly increased until the "switch-on voltage" $V_{\mathrm{sw}}$ was reached. At this point the emission current switches on to a "nearly saturated" value called the "switch-on current" $I_{\mathrm{sw}}$ (see red marked points in Fig. 4A). In this experiment we found $V_{\mathrm{sw}}=2,400 \mathrm{~V}$ and $I_{\mathrm{sw}}=1.5 \mu \mathrm{A}$. It has already been found in earlier work (Latham and Mousa, 1986) that after switch-on the current increases relatively slowly, so we did not consider it necessary to explore this upper part of the voltage range in the present experiments. Partly, this was a precaution to avoid accidentally destroying the emitter.

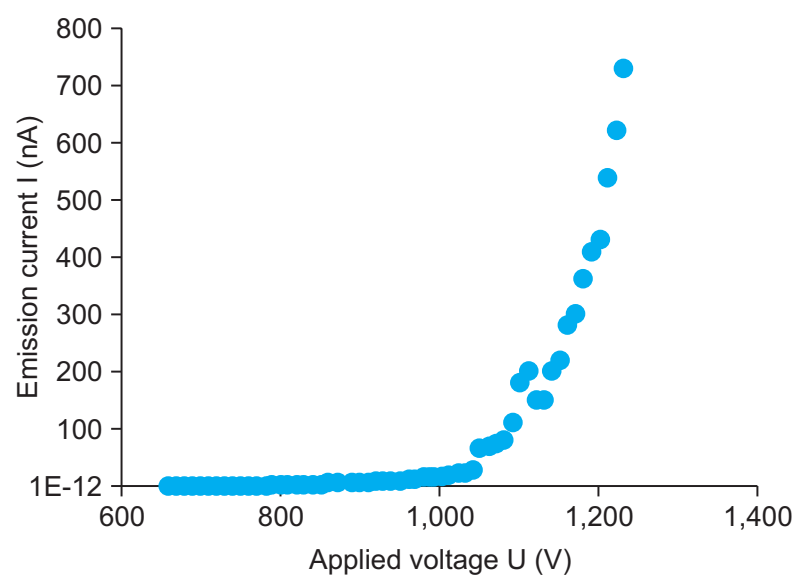

Fig. 2. The current-voltage $I(V)$ characteristics of a tungsten emitter (emitter 1) before coating.
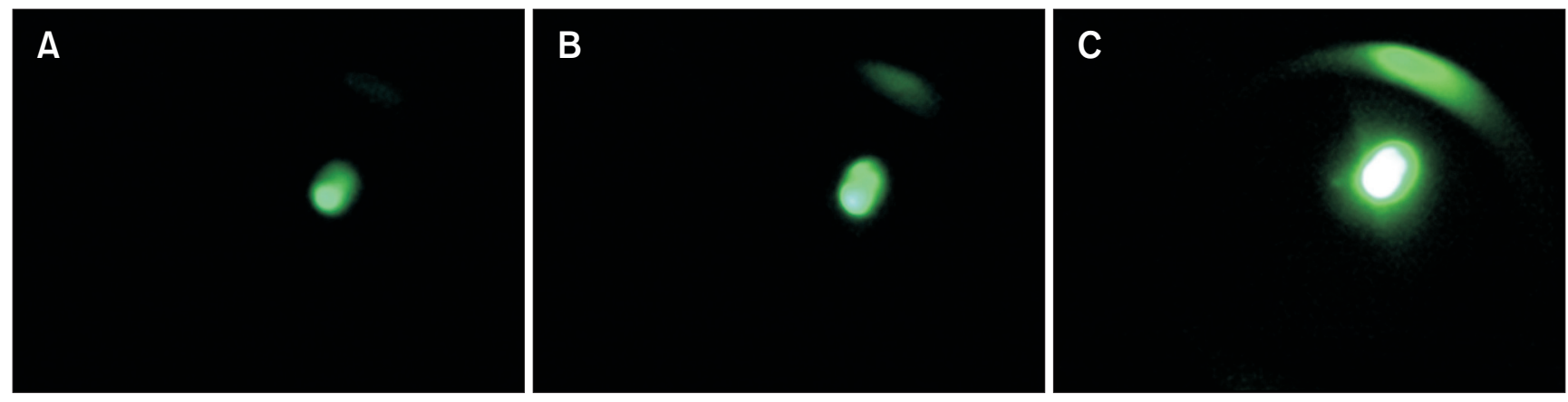

Fig. 3. Field electron emission micrographs of emitter 1 before coating, taken as voltage increases, at the following $(V, I)$ values. (A) $870 \mathrm{~V}, 5 \mathrm{nA}$; (B) $960 \mathrm{~V}, 11$ nA; (C) 1,050 V, 64 nA.

Table 1. Comparison of current-voltage-based data in the four cases* of tungsten micro-point emitters

\begin{tabular}{|c|c|c|c|c|c|c|c|c|}
\hline \multirow{2}{*}{ Property } & \multicolumn{2}{|c|}{ Emitter 1} & \multicolumn{2}{|c|}{ Emitter 2} & \multicolumn{2}{|c|}{ Emitter 3} & \multicolumn{2}{|c|}{ Emitter 4} \\
\hline & Voltage (V) & Current & Voltage (V) & Current & Voltage (V) & Current & Voltage (V) & Current \\
\hline \multicolumn{9}{|l|}{ Uncoated emitter } \\
\hline Onset values & 650 & $4.5 \mathrm{pA}$ & 390 & $8 \mathrm{pA}$ & 800 & $76 \mathrm{pA}$ & 1,100 & $66 \mathrm{pA}$ \\
\hline Upper values & 1,230 & $720 \mathrm{nA}$ & 1,000 & $1.1 \mu \mathrm{A}$ & 1,800 & $770 \mathrm{nA}$ & 2,100 & $520 \mathrm{nA}$ \\
\hline Circuit resistance at onset & \multicolumn{2}{|c|}{$140 \mathrm{~T} \Omega$} & \multicolumn{2}{|c|}{$49 \mathrm{~T} \Omega$} & \multicolumn{2}{|c|}{$11 \mathrm{~T} \Omega$} & \multicolumn{2}{|c|}{$17 \mathrm{~T} \Omega$} \\
\hline Circuit resistance at upper point & \multicolumn{2}{|c|}{$1.7 \mathrm{G} \Omega$} & \multicolumn{2}{|c|}{$0.91 \mathrm{G} \Omega$} & \multicolumn{2}{|c|}{$2.3 \mathrm{G} \Omega$} & \multicolumn{2}{|c|}{$4.0 \mathrm{G} \Omega$} \\
\hline Resistance ratio (onset/upper point) & \multicolumn{2}{|c|}{84,000} & \multicolumn{2}{|c|}{54,000} & \multicolumn{2}{|c|}{4,500} & \multicolumn{2}{|c|}{4,100} \\
\hline \multicolumn{9}{|l|}{ Coated emitter } \\
\hline Switch-on values $\left(V_{\mathrm{sw}}, I_{\mathrm{sw}}\right)$ & 2,400 & $1.5 \mu \mathrm{A}$ & 6,900 & $1.2 \mu \mathrm{A}$ & 2,300 & $5.4 \mu \mathrm{A}$ & 2,500 & $7.3 \mu \mathrm{A}$ \\
\hline First decreasing run - bottom & 700 & $8.8 \mathrm{pA}$ & 500 & $8.3 \mathrm{pA}$ & 600 & $9.1 \mathrm{pA}$ & 600 & $88 \mathrm{pA}$ \\
\hline Second increasing run - bottom & 700 & $6.7 \mathrm{pA}$ & 1,100 & $11 \mathrm{pA}$ & 400 & $11 \mathrm{pA}$ & 500 & $11 \mathrm{pA}$ \\
\hline Second increasing run - top & 1,900 & $1.1 \mu \mathrm{A}$ & 2,900 & $1 \mu \mathrm{A}$ & 1,300 & $780 \mathrm{nA}$ & 1,300 & $440 \mathrm{nA}$ \\
\hline \multicolumn{9}{|l|}{ Other data } \\
\hline Post-switch-on circuit resistance & \multirow{2}{*}{\multicolumn{2}{|c|}{$\begin{array}{c}1.6 \mathrm{G} \Omega \\
\text { Very good }\end{array}$}} & \multicolumn{2}{|c|}{$5.8 \mathrm{G} \Omega$} & \multicolumn{2}{|c|}{$420 \mathrm{M} \Omega$} & \multicolumn{2}{|c|}{$340 \mathrm{M} \Omega$} \\
\hline Image quality (coated emitter) & & & \multicolumn{2}{|c|}{ Medium } & \multicolumn{2}{|c|}{ Limited } & \multicolumn{2}{|c|}{ Limited } \\
\hline
\end{tabular}

*Coated by: (1) Clark Electromedical Instruments epoxylite resin; (2) Epidian 6 epoxy resin (based on Bisphenol A); (3) A Radianox solution of colloidal graphite; (4) Molyslip 2001 EE compound (MoS2 and MoS). 
Starting from the switch-on voltage, the voltage was then decreased: the blue marked points in Fig. $4 \mathrm{~A}$ shows $I(V)$ values recorded during this "decreasing" sequence. FEM images were observed during the process of decreasing the voltage, and a set of micrographs were recorded, as shown in Fig. 5. An interval of 15 minutes was allowed between each photograph. What Fig. 4A and 5 clearly demonstrate is that, certainly at a gross level, the emission current distribution was relatively stable, both over time and over a significant range of voltage.

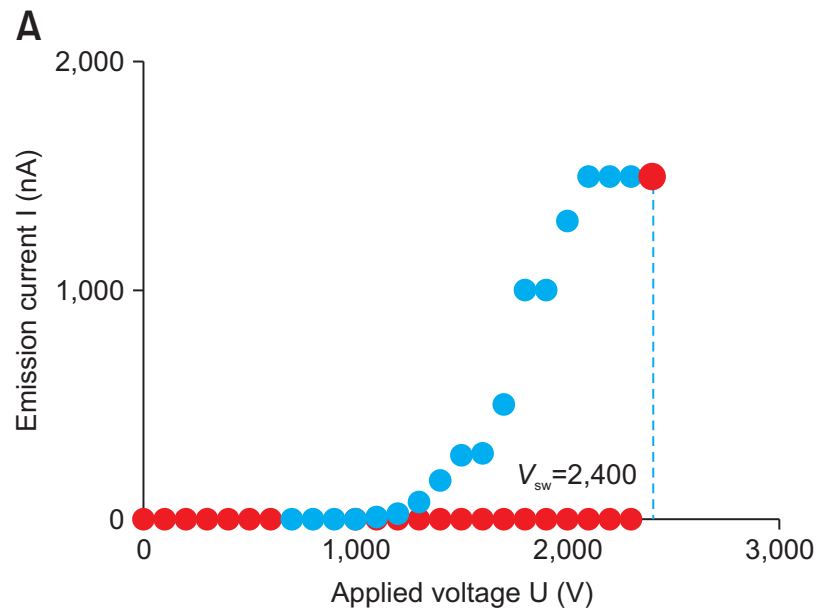

After the voltage had been decreased to zero, it was then increased again up to close to the original switch-on voltage. The resulting $I(V)$ plot is shown in Fig. 4B. In this "postswitch-on" case, the $I(V)$ plot qualitatively resembles that found in the previous decreasing sequence, rather than the plot found in the first increasing sequence, although numerical values are not exactly the same. This shows clearly that the switch-on event has induced some permanent or long-time-scale change in the coating. This change is thought

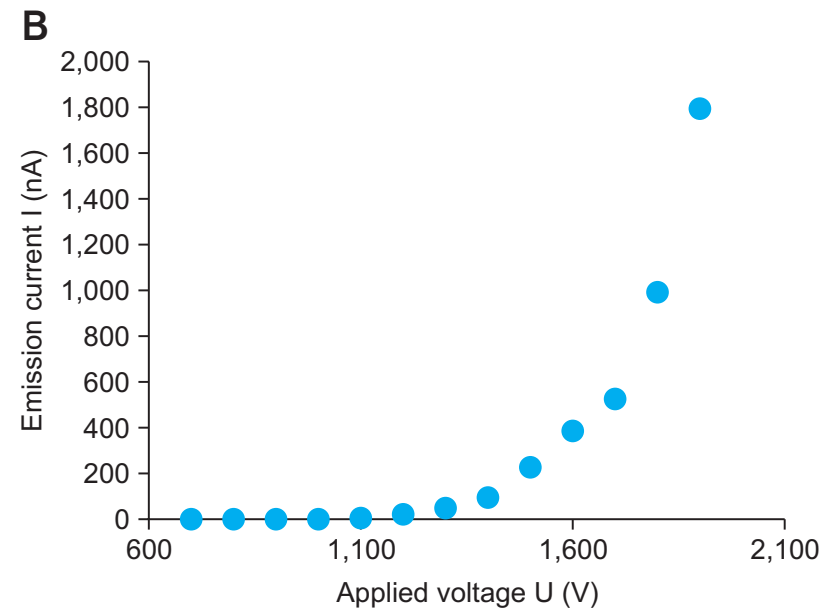

Fig. 4. $I(V)$ characteristics of emitter 1 after coating with Clark Electromedical Instruments epoxylite resin. (A) The red dots show the first voltage-increasing ( $V$-increasing) data-set, up to switch-on at $V_{\mathrm{sw}}=2,400 \mathrm{~V}, I_{\mathrm{sw}}=1.5 \mu \mathrm{A}$; the blue dots show the first $V$-decreasing data-set. (B) The second $V$-increasing data-set.
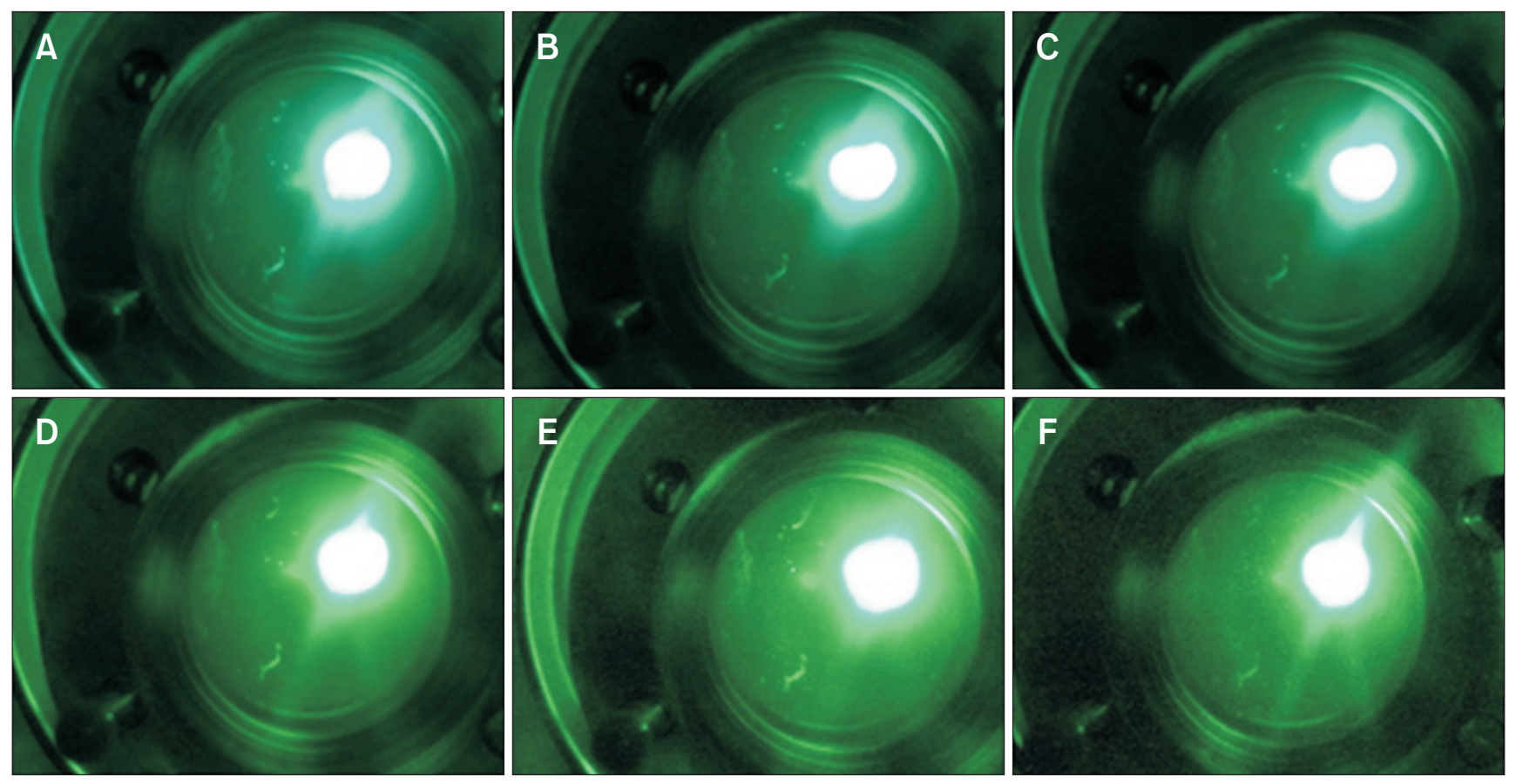

Fig. 5. Field electron emission micrographs of coated emitter 1 taken during the first voltage-decreasing sequence, at the following voltage and current values. (A) 2,400 V, $1.5 \mu \mathrm{A}$; (B) 2,300 V, $1.5 \mu \mathrm{A}$; (C) 2,200 V, $1.5 \mu \mathrm{A}$; (D) 1,900 V, $1.3 \mu \mathrm{A}$; (E) 1,800 V, $1 \mu \mathrm{A}$; (F) $1,700 \mathrm{~V}, 1 \mu \mathrm{A}$. The time separation between each two consecutive images is 15 minutes. 
to be associated with the formation of a conducting channel through the coating, as first suggested by Latham and Mousa (1986), but the exact nature of the channel remains unclear.

\section{Other Composite Emitters}

We then carried out procedurally identical sets of experiments with the other three coatings. Results were qualitatively similar to those described above for the epoxylite resin coating. A switch-on phenomenon occurred in all cases, and the FEM images after switch-on were relatively stable over a range of times and voltages. However, quantitative details of the $I(V)$ characteristics and the details of the FEM images varied for the four differently coated emitters.

The resulting data are presented in the following way. Fig. 6,7 , and 8 show the $I(V)$ characteristics for, respectively, emitters 2, 3 and 4 . The left-hand plot shows the first voltage- increasing ( $V$-increasing; red dots) and $V$-decreasing (blue dots) sequences; the right-hand plot shows the second $V$-increasing sequence. Fig. 9 then shows "before coating" and "after coating" images (vertically arranged pairs) for each of emitters 2, 3 and 4 (arranged left to right).

Table 1 shows relevant voltage and current ranges. It also shows values of the measured circuit resistance $R_{\mathrm{m}}$ defined by

$$
R_{\mathrm{m}}=V / I
$$

Note that $R_{\mathrm{m}}$ is not the emission resistance $R_{\mathrm{e}}$ associated with the emitter by itself (Forbes et al., 2015) but is a particular value of the total (voltage-dependent) resistance $R_{\mathrm{m}}$ seen by the voltage supply, for given physical circumstances of the circuit. For the uncoated emitters, Table 1 shows $R_{\mathrm{m}}$-values at onset and at the top of the voltage range used, and also
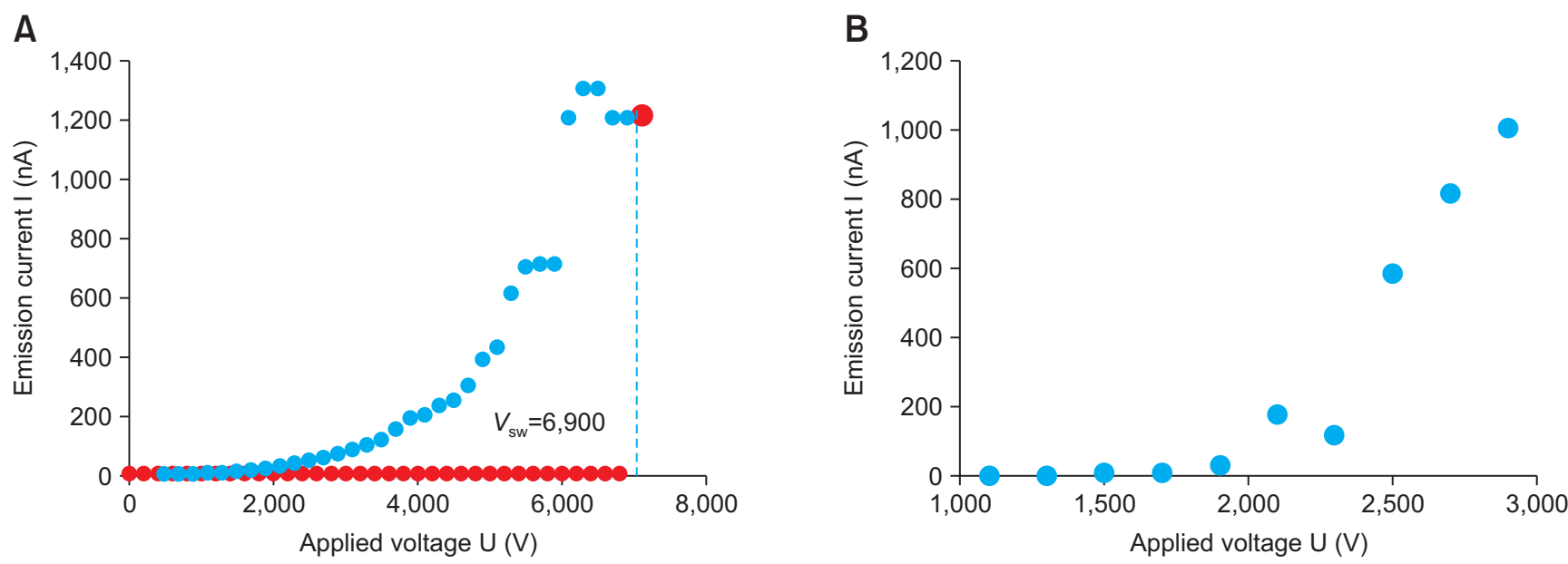

Fig. 6. $I(V)$ characteristics of emitter 2 after coating with Epidian 6 epoxy resin (based on bisphenol A). (A) The red dots show the first voltage-increasing ( $V$-increasing) data-set, up to switch-on at $V_{\text {sw }}=6,900 \mathrm{~V}, I_{\text {sw }}=1.2 \mu \mathrm{A}$; the blue dots show the first $V$-decreasing data-set. (B) The second $V$-increasing data-set.
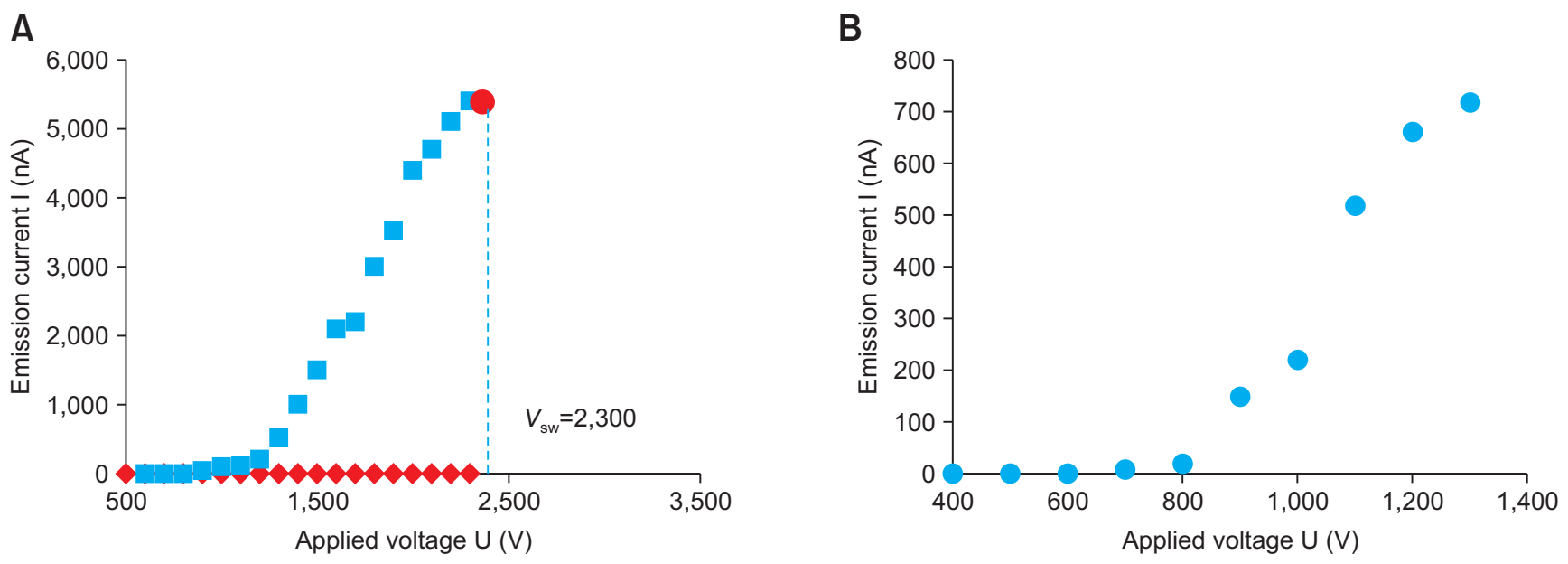

Fig. 7. $I(V)$ characteristics of emitter 3 after coating with a Radianox compound of colloidal graphite. (A) The red dots show the first voltage-increasing ( $V$-increasing) data-set, up to switch-on at $V_{\text {sw }}=2,500 \mathrm{~V}, I_{\text {sw }}=5.4 \mu \mathrm{A}$; the blue dots show the first $V$-decreasing data-set. (B) The second $V$-increasing data-set. 

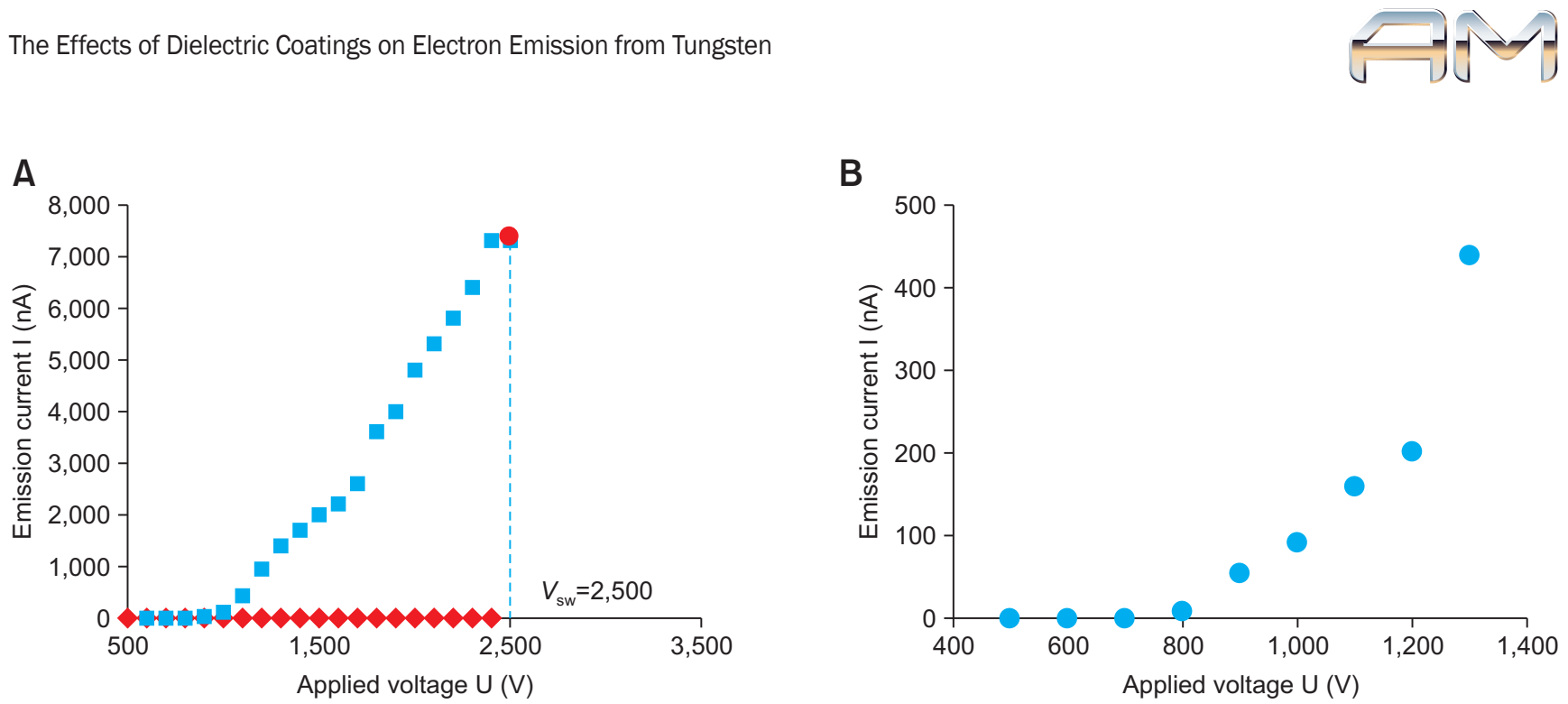

Fig. 8. $I(V)$ characteristics of emitter 4 after coating with Molyslip $2001 \mathrm{EE}$ compound (MoS2 and MoS). (A) The red dots show the first voltage-increasing ( $V$-increasing) data-set, up to switch-on at $V_{\text {sw }}=2,500 \mathrm{~V}, I_{\text {sw }}=7.3 \mu \mathrm{A}$; the blue dots show the first $V$-decreasing data-set. (B) The second $V$-increasing data-set.
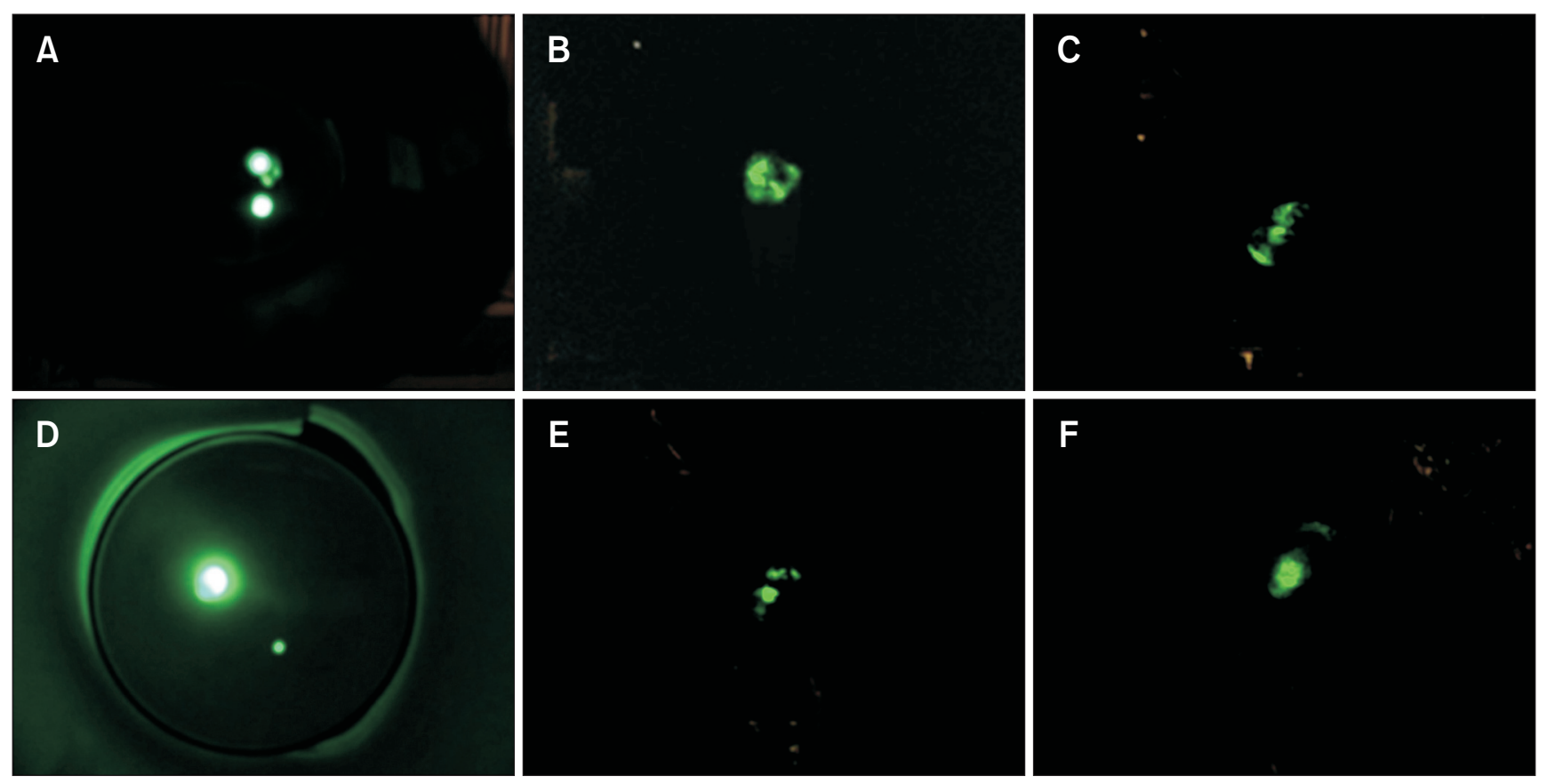

Fig. 9. For each of emitters 2, 3 and 4, in sequence left to right, this figure shows typical FEM images before (A-C), and after (D-F) coating. For each emitter, the "before" and "after" images are aligned vertically. Images were taken at the following data points: (A) $1,000 \mathrm{~V}, 1.1 \mu \mathrm{A} ;(\mathrm{B}) 1,800 \mathrm{~V}, 0.8 \mu \mathrm{A} ;(\mathrm{C}) 2,100 \mathrm{~V}, 0.52$ $\mu \mathrm{A}$; (D) 6,900 V, $1.2 \mu \mathrm{A}$; (E) 2,300 V, $5.4 \mu \mathrm{A}$; (F) $2500 \mathrm{~V}, 7.3 \mu \mathrm{A}$.

the ratio of these values. For the coated emitters, the circuit resistance immediately post switch-on is shown. The lowest section of the Table 1 also records a qualitative assessment of the usefulness of the observed emission distribution for the purpose of developing electron sources.

\section{DISCUSSION AND CONCLUSIONS}

The most important finding from this work is that the switch- on phenomenon occurs with all of the four different dielectric coatings used. Whilst this is not entirely surprising, it is something that needed to be investigated. What this means is that the basic explanation of the phenomenon needs to be relatively general, and not specific to particular individual materials. The hypothesis of conducting-channel formation is a general explanation of this kind. Of course, other hypotheses may emerge. Another important finding is that, at the gross level, the emission images are in all cases relatively stable over 
a range of times and applied voltages. This is a necessary requirement if an emitter is to be used as an electron source.

As regards the more detailed suitability of these emitters as potential electron sources, the data in Table 1 exhibit conflicting trends. The lower values of the "post-switch-on circuit resistance" $R_{\mathrm{sw}}$ for emitters 3 and 4 appears to suggest that the related coatings would allow greater current to be achieved at lower voltages. On the other hand, the FEM images suggest that emitter 1 (and, to a lesser extent, emitter 2) would be more suitable, because the emission occupies larger angle in the field of view. The particularly large values of $V_{\mathrm{sw}}$ and $R_{\mathrm{sw}}$ for emitter 2 could arise because the coating in question (Epidian 6) solidifies to form a very hard layer on the apex of the underlying tungsten emitter; this could perhaps have an advantage in prolonging emitter lifetime.

Another feature of Table 1 is that the circuit-resistance data for emitters 3 and 4, before coating, look appreciably different from the data for emitters 1 and 2, before coating. This suggests the possibility that the properties (maybe shape and size) of the uncoated tungsten emitters may also be playing a role.

Clearly, further investigation of composite emitters would be worthwhile. In our view, the most obvious next step would be to investigate the properties of a significant number of emitters of type 1, to see how reproducible are the properties we have found here for a single emitter of this type. In particular, the FEM images found here for a type 1 coated emitter are somewhat similar to, but not identical with, the images found previously for an emitter of this type (Al-Qudah et al., 2015), so obviously some variability is to be expected. It would also be helpful to know whether the shape and size of the uncoated tungsten emitter has any significant influence on coated-emitter results, and if so then what influence.

In summary, we have made a preliminary investigation of the emission properties of tungsten micro-point emitters coated with four different types of dielectric coating, and have found that a "switch-on" phenomenon occurs in all cases, and that the post-switch-on emission images are (at the gross level) stable over a range of times and voltage values. We have selected the emitter type "tungsten coated with Clark Electromedical Instruments epoxylite resin" as the best candidate for further investigations.

\section{CONFLICT OF INTEREST}

No potential conflict of interest relevant to this article was reported.

\section{ACKNOWLEDGMENTS}

Ala'a M. Al-Qudah would like to express gratitude to the Scientific Research Support Fund (SRSF) in the Hashemite Kingdom of Jordan for financial support that enabled completing this Research work. We thank Dr Richard G. Forbes for reading a draft version of this manuscript and making suggestions for improvement.

\section{REFERENCES}

Al-Qudah A, Mousa M S, and Fischer A (2015) Effect of insulating layer on the field electron emission performance of nano-apex metallic emitters. IOP Conf. Ser:: Mater. Sci. Eng. 92, 012021.

Crewe A V, Isaacson M, and Johnson D (1969) A simple scanning electron microscope. Rev. Sci. Instrum. 40, 241-246.

Crewe A V and Wall J (1970) A scanning microscope with 5 Å resolution. J. Mol. Biol. 48, 375-393.

Crewe A V, Wall J, and Welter L M (1968) A high-resolution scanning transmission electron microscope. J. Appl. Phys. 39, 5861-5868.

Dyke W P and Dolan W W (1956) Field emission. Adv. Electronics Electron Phys. 8, 89-185.

Forbes R G (2008) Description of field emission current/voltage characteristics in terms of scaled barrier field values. J. Vac. Sci. Technol. B 26, 209-213.

Forbes R G, Deane J H B, Fischer A, and Mousa M S (2015) FowlerNordheim plot analysis: a progress report. Jo. J. Phys. 8, 125-147; arXiv 1504.06134v7.
Latham R V and Mousa M S (1986) Hot electron emission from composite metal-insulator micropoint cathodes. Appl. Phys. 19, 699-713.

Madanat M A, Mousa M S, Al-Rabadi A N, and Fischer A (2015) Electron microscopy-based performance evaluation of various tungsten fieldemitter tips Apex radii. Jo. J. Phys. 8, 79-85.

Melmed A J (1991) The art and science and other aspects of making sharp tips. J. Vac. Sci. Technol. B 9, 601-608.

Mousa M S (1990) Cold cathode field emission using both Al-resin and Au-resin coatings on tungsten substrate. Surf. Sci. 231, 142-148.

Mousa M S and Al Share M (1999) Study of the MgO-coated W emitters by field emission microscopy. Ultramicroscopy 79, 195-202.

Mousa M S, Fischer A, and Mussa K O (2012) Metallic and composite micropoint cathodes: aging effect and electronic and spatial characteristics. Jo. J. Phys. 1, 21-26.

Mousa M S, Karpowicz A, and Surma S (1994) Switch-on phenomena in field electron and field ion microscopy. Vacuum 45, 249-254.

Zhu W (2001) (ed.) Vacuum Microelectronics (Wiley, New York). 